\title{
Research on the Selection of Supply Chain Marketing Models Based on E-commerce Service Levels
}

\author{
Weijia Ding*, Liyun Wu \\ School of Energy Science and Engineering, Henan Polytechnic University, Jiaozuo 454000, China \\ *Corresponding author: Weijia Ding, Dwjiejob@yeah.net
}

\begin{abstract}
Based on the game theory, the service sensitivity coefficient is introduced to construct four marketing game models, which include a single flagship store, a single self-operated store, a direct sales-flagship store, and a direct sales-self-operated store, in combination with numerical analysis methods to analyze manufacturers and e-commerce platforms in different situations. The study found that the service levels affected the profit of each entity in the supply chain. The service levels of self-operated stores were higher than those of the flagship stores, and the opening of direct sales channels had a stimulating effect on the service levels of e-commerce platforms to a certain extent. In consideration of the service levels and the ability to build direct sales channels, the direct sales-flagship store marketing model is the best choice for manufacturers whereas ecommerce platforms are more inclined to open self-operated stores. However, the opening of manufacturers' direct sales channels is not necessarily beneficial to e-commerce platforms.
\end{abstract}

Keywords: E-commerce; Marketing mode; Service level; Game theory

Publication date: August 2021; Online publication: August 30, 2021

\section{Introduction}

The $46^{\text {th }}$ Statistical Report on China's Internet Development Status, released by China Internet Network Information Center (CNNIC), showed that online retail sales in the first half of 2020 would reach 5,150.1 billion with a year-on-year increase of $7.3 \%$. In this environment, in order to raise profits, e-commerce platforms are no longer willing to only be service providers for manufacturers, but they have started to develop self-operated products and services, such as JD self-operated stores, and at the same time, manufacturers have also begun to develop direct sales channels, such as Gree - Dong Mingzhu's shop. These behaviors are bound to cause brand-new price, service, and channel competition issues. Therefore, considering the choice of supply chain marketing model based on the service level is worthy of study.

At present, the research on supply chain marketing models mainly focuses on the impact of manufacturers' introduction of direct sales channels, business-to-consumer (B2C) e-commerce platform marketing model, and service levels on supply chain management. The research on the introduction of direct sales channels by manufacturers mainly emphasizes on the influence of direct sales channels opening by manufacturers on the decision-making of supply chain members ${ }^{[1]}$, of which on this basis, factors such as consumer behavior ${ }^{[2]}$ and product differentiation ${ }^{[3]}$ are considered as the influence in the choice of manufacturers' marketing model. Most of the above-mentioned introduce direct sales channels on the basis of traditional channels so as to discuss the influence of direct sales channels opening by manufacturers on supply chain management. Regarding the research on the marketing model of B2C e-commerce platform, it mainly explores whether the e-commerce platform is open ${ }^{[4]}$ in addition to the interaction between the 
behavior of the manufacturer and the e-commerce platform ${ }^{[5]}$. All the above studies are research regarding manufacturers or e-commerce platforms as the sole decision-maker, failing to comprehensively consider the balance between the two decision-making bodies. The research on the influence of service level on the decision-making of supply chain members mainly focuses on three aspects: the influence of service level on consumer demand ${ }^{[6]}$ and supply chain decision-making ${ }^{[7]}$ in the traditional supply chain; the influence of logistics services on the decision-making of supply chain members ${ }^{[8]}$ in online sales; the service competition ${ }^{[9]}$ caused by channel competition. Most of the above studies did not consider the impact of the difference in service levels, between platform self-operated stores and official flagship stores, on the supply chain marketing model.

Therefore, this article focuses on the secondary supply chain dominated by B2C e-commerce platforms, construct four game models which include a single flagship store, a single self-operated store, a direct salesflagship store, and a direct sales-self-operated store, as well as discusses the supply chain members' choice of marketing model and the value of service level in strategic decision-making.

\section{Problem description and assumptions}

\subsection{Problem description}

This article considers a secondary supply chain system, which consist of a manufacturer and an e-commerce platform, with the e-commerce platform as the leader. According to the characteristics of online sales channels, the marketing model is divided into four: single flagship store; single self-operated store; direct sales-flagship store; direct sales-self-operated store (Figure 1).
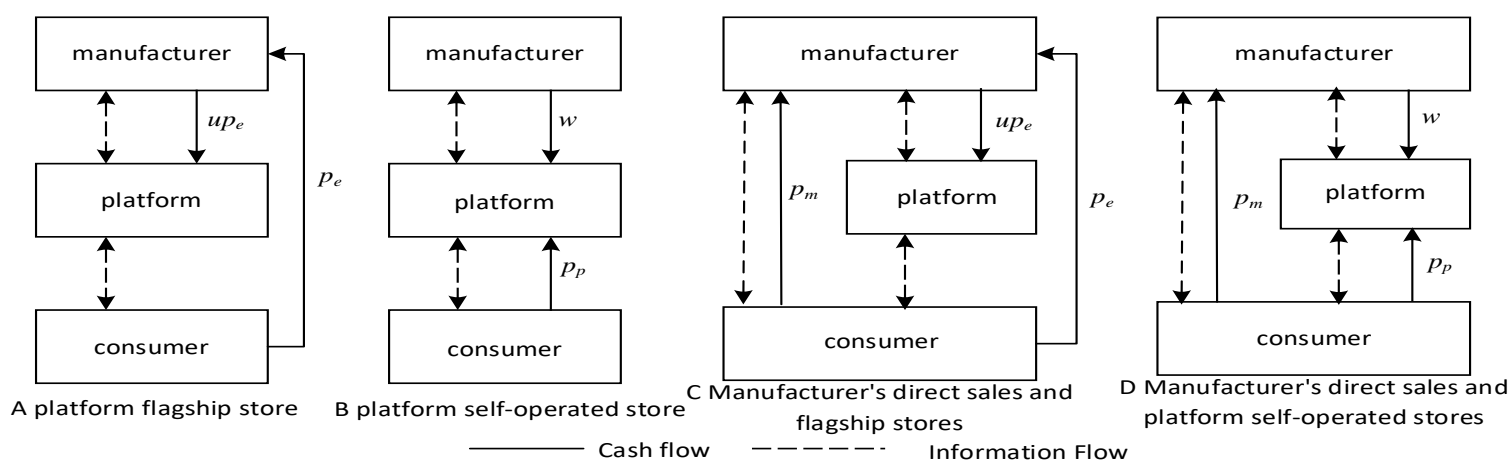

Figure 1. Four different marketing models, consisting of manufacturers and platform vendors

In the single flagship store model, the manufacturer cooperates with the $\mathrm{B} 2 \mathrm{C}$ e-commerce platform where the manufacturer holds the ownership and pricing power of the product as well as bears the service cost whereas the e-commerce company is only responsible for the sales. The manufacturer would then give the e-commerce platform a certain percentage of commission as compensation based on the sales. In the single self-operated store model, the manufacturer provides wholesales products to the e-commerce platform, and the e-commerce platform has the ownership, pricing power of the product, and it bears the service cost. In the direct sales-flagship store model, the manufacturer retains the flagship store of the ecommerce platform and at the same time, open up an online direct sales channel. The pricing power and ownership of the products under both channels belong to the manufacturer while the e-commerce platform only provides services. In the direct sales-self-operated store model, the manufacturer provides wholesale products to the e-commerce platform and at the same time, opens an online direct sales channel to sell products. The ownership and pricing power of the products sold on the e-commerce platform belong to the e-commerce platform whereas and the ownership and pricing power of the products sold by the direct sales channel belong to the manufacturer. 


\subsection{Basic assumptions and symbol description}

This study makes basic assumptions about the model.

1) All sales channels sell the same product, regardless of the product's manufacturing cost and channel fixed cost.

2) The total demand for products in the market is standardized to 1. After the direct sales channel is opened, the transfer ratio of consumers to the direct sales channel is set to $a(0<a<1)$.

3) When the e-commerce platform provides the service level $s$, the corresponding cost to be paid for this is $C(s)=k s^{2} / 2$, in which for simple calculation, suppose that $k=1{ }^{[10]}$. Compared with the professional service methods provided by e-commerce platforms, the service methods and conditions that manufacturers can adopt are very scarce so the service levels of the two are not comparable. Hence, it is assumed that the service level of the manufacturer's online direct sales channel is 0 .

4) A data survey shows that the commission rate of Tmall flagship store is $0.1 \% \sim 10 \%$, JD is $1 \% \sim 10 \%$, Walmart is $6 \% \sim 20 \%$. In order to make the research results more applicable, the hypothesis is $0<\rho<0.5$.

The definition of the symbols in the model is shown in Table 1.

Table 1. Symbols and their meanings

\begin{tabular}{cl}
\hline Symbol & \multicolumn{1}{c}{ Meaning } \\
\hline$a$ & Consumer transfer ratio \\
$s_{1} / s_{2}$ & Service level under the flagship store/self-operated store marketing model \\
$c$ & The unit sales cost of the manufacturer's online direct sales channel \\
$\theta$ & Consumers' sensitivity to services \\
$\beta$ & Cross price sensitivity coefficient \\
$u$ & The percentage of commission received by the flagship store \\
$w^{i}$ & Wholesale prices of products in different marketing models \\
$p_{e}^{i} / p_{p}^{i} / p_{m}^{i}$ & Sales prices under different marketing models \\
\hline
\end{tabular}

Subscript " $e$ " in Table 1 represents the platform flagship store, " $p$ " represents the platform selfoperated store, and " $m$ " represents the manufacturer's online direct sales channel. Superscript " $i$ " = $\mathrm{A} / \mathrm{B} / \mathrm{C} / \mathrm{D}$, represents the single flagship store/single self-operated store/direct sales-flagship store/direct sales-self-operated store marketing model, respectively. The superscript "*" in the text indicates the optimal decision.

\section{Model establishment and solution}

\subsection{Single flagship store marketing model}

When the manufacturer only establishes an official flagship store to sell products on the e-commerce platform, the sales channel has stable demand. Based on the above assumptions and with reference to literature, a demand function that depends on the price and service level under a single flagship store marketing model is constructed. The linear demand function of the sales channel of the e-commerce platform is as follows:

$$
D_{p}\left(p_{e}, \mathrm{~s}_{1}\right)=1-p_{e}+\theta s_{1}
$$


The profits of the manufacturer and the e-commerce platform are as follows:

$$
\begin{aligned}
\pi_{m} & =(1-u) p_{e} D_{p} \\
\pi_{p} & =u p_{e} D_{p}-\frac{s_{1}^{2}}{2}
\end{aligned}
$$

According to the Stackelberg game theory, first, the e-commerce platform determines the service level, and then the manufacturer decides the product price based on the principle of maximizing its own interests. Solving by the reverse induction method, substitute equation (1) into equation (2) and find the first-order partial derivative of $p_{e}$. The reaction function of $p_{e}$ with respect to $s_{1}$ can be derived: $p_{e}=1 / 2\left(1+\theta s_{1}\right)$. Substituting it into equation (3) to find the derivative of $s_{1}, s_{1}^{A^{*}}, p_{e}^{A^{*}}$ can be deduced. Substituting $s_{1}^{A^{*}}, p_{e}^{A^{*}}$ to get the equilibrium solutions in this model:

$$
s_{1}^{A *}=\frac{\theta u}{2-\theta^{2} u}, \quad p_{e}^{A *}=\frac{1}{2-\theta^{2} u}, \quad \mathrm{D}_{p}^{A *}=\frac{1}{2-\theta^{2} u}, \pi_{m}^{A *}=\frac{1-u}{\left(\theta^{2} u-2\right)^{2}}, \pi_{p}^{A *}=\frac{u}{4-2 \theta^{2} u}
$$

Conclusion 1: Under the single flagship store marketing model, each optimal decision is affected by the service sensitivity coefficient and the commission ratio.

$$
\frac{\partial s_{1}^{A *}}{\partial \theta}>0, \frac{\partial D_{p}^{A *}}{\partial \theta}>0, \frac{\partial \pi_{m}^{A *}}{\partial \theta}>0, \frac{\partial \pi_{p}^{A *}}{\partial \theta}>0 ; \quad \frac{\partial s_{1}^{A *}}{\partial u}>0, \frac{\partial D_{p}^{A *}}{\partial u}>0, \frac{\partial \pi_{m}^{A *}}{\partial u}>0, \frac{\partial \pi_{p}^{A *}}{\partial u}>0
$$

Conclusion 1 shows that under a single flagship store marketing model, first, as service sensitivity increases, service level increases, product demand increases, and the profits of the manufacturer and ecommerce platform increase. Second, as commissions increase, the service level increases, demand increases, the profits of the manufacturer and e-commerce platform increase. In other words, the increase in commissions would not reduce the profits of manufacturers.

\subsection{Single self-operated store marketing model}

Under the single self-operated store marketing model, the sales channel demand function of the e-commerce platform is as follows:

$$
D_{p}\left(p_{p}, \mathrm{~s}_{2}\right)=1-p_{p}+\theta s_{2}
$$

The sales profit functions of the manufacturer and the e-commerce platform are as follows:

$$
\begin{gathered}
\pi_{m}=w D_{p} \\
\pi_{p}=\left(p_{p}-w\right) D_{p}-\frac{s_{2}^{2}}{2}
\end{gathered}
$$

According to the game theory, the platform first determines the product sales price $p_{p}$ and service level $s_{2}$, then the manufacturer determines the wholesale price $w$. This model cannot be derived directly. Assuming that the marginal profit of the platform unit is $m_{1}=p_{p}-w$, use reverse induction to obtain various equilibrium solutions: 


$$
s_{2}^{B^{*}}=\frac{\theta}{4-\theta^{2}}, \quad p_{p}^{B^{*}}=\frac{3}{4-\theta^{2}}, \quad w^{B^{*}}=\frac{1}{4-\theta^{2}}, \quad \mathrm{D}_{p}^{\beta^{*}}=\frac{1}{4-\theta^{2}} \quad \pi_{m}^{B^{*}}=\frac{1}{\left(\theta^{2}-4\right)^{2}}, \quad \pi_{p}^{B^{*}}=\frac{1}{8-2 \theta^{2}}
$$

Conclusion 2: Under the single self-operated store marketing model, each optimal decision is only affected by the service sensitivity coefficient.

$$
\frac{\partial s_{2}^{B^{*}}}{\partial \theta}>0, \frac{\partial w^{B *}}{\partial \theta}>0, \frac{\partial D_{p}^{B^{*}}}{\partial \theta}>0, \frac{\partial \pi_{m}^{B *}}{\partial \theta}>0, \frac{\partial \pi_{p}^{B^{*}}}{\partial \theta}>0
$$

Conclusion 2 shows that as service sensitivity increases, service level increases, product demand increases, and the e-commerce platform's profit increases. At the same time, the wholesale price increases, and the manufacturer's profit increases. Combining with conclusion 1, it shows that under a single marketing model, improving the service level is beneficial to manufacturers and e-commerce platforms for service-sensitive consumers.

\subsection{Direct sales-flagship store marketing model}

In the direct sales-flagship store marketing model, the service and pricing strategies of the two sales channels belonging to the manufacturer and the e-commerce platform are different. The opening of the manufacturer's direct sales channel will inevitably transfer a certain percentage $(a)$ of consumers, resulting in channel competition. The establishment of the manufacturer and the e-commerce platform depends on the demand function of prices and services, respectively. Therefore, the linear demand functions of the manufacturer's direct sales channel and the e-commerce platform sales channel are as follows:

$$
\begin{gathered}
D_{m}\left(p_{e}, p_{m}\right)=a-p_{m}+\beta p_{e} \\
D_{p}\left(p_{m}, p_{e}, s_{1}\right)=(1-a)-p_{e}+\beta p_{m}+\theta s_{1}
\end{gathered}
$$

The profits of the manufacturer and the e-commerce platform are as follows:

$$
\begin{gathered}
\pi_{m}=\left(p_{m}-c\right) D_{m}+(1-u) p_{e} D_{p} \\
\pi_{p}=u p_{e} D_{p}-\frac{s_{1}^{2}}{2}
\end{gathered}
$$

The solution method of this model is the same as in 3.1, hence the solution process is no longer listed here. The optimal decisions are as follows:

$$
\begin{aligned}
s_{1}^{C *} & =\frac{\theta u\left(8(1-a)(u-1)^{2}+4(a+c)(u-1)^{2} \beta+4(a-1) H \beta-(u-1)\left(-2(a+c)+(a+3 c) u \beta^{3}\right)\right.}{F^{2}+G} \\
p_{e}^{C *} & =\frac{\left(2 c(u-1)-H+c(2-u) \beta^{2}\right) F+(c(u-1) I+2 c H \beta) \theta^{2}+(2 a(u-1)+a H) F}{F^{2}+G} \\
p_{m}^{C *} & \left.=\frac{(-2(a-1)(u-1)+a(u-2) \beta+c u \beta) F+2(a-c)(u-1) u \beta \theta^{2}}{F^{2}+G} \beta+2\left(\beta^{2}-1\right)+(a-c) u\left(4-4 \beta^{2}+u\left(3 \beta^{2}-4\right)\right) \theta^{2}\right) \\
D_{m}^{C *} & =\frac{F(u-1)\left(u \beta+a(\beta-1)\left(-2+(u-2) \beta+F^{2}+G\right.\right.}{F^{2}+G} \\
D_{p}^{C *} & =\frac{F\left(-2(a-1)(u-1)+c(u-2) \beta+a u \beta+(a-1)(u-2) \beta^{2}-c(u-2) \beta^{3}+(a-c) u \beta\left(2-2 u+(u-2) \beta^{2}\right) \theta^{2}\right.}{F^{2}+G}
\end{aligned}
$$


Among them, $F=4(u-1)+(u-2)^{2} \beta^{2}, \quad H=(u-1)(u-2) \beta \quad, \quad G=4(u-1) \mathrm{u}\left(2-2 \mathrm{u}+(\mathrm{u}-2) \beta^{2}\right) \theta^{2}$, $I=4-4 u+(u-2) \beta^{2}$.

The optimal profit value is too complicated and will not be listed here.

Conclusion 3:

$$
\begin{gathered}
\frac{\partial s_{1}^{C *}}{\partial \theta}>0, \frac{\partial D_{m}^{C *}}{\partial \theta}>0, \frac{\partial D_{p}^{C *}}{\partial \theta}>0, \frac{\partial \pi_{m}^{C *}}{\partial \theta}>0, \frac{\partial \pi_{p}^{C *}}{\partial \theta}>0 \\
\frac{\partial s_{1}^{C *}}{\partial u}>0, \frac{\partial D_{m}^{C *}}{\partial u}<0, \frac{\partial D_{p}^{C *}}{\partial u}>0, \frac{\partial \pi_{m}^{C *}}{\partial u}<0, \frac{\partial \pi_{p}^{C *}}{\partial \theta}>0 \\
\frac{\partial s_{1}^{C *}}{\partial a}<0, \frac{\partial D_{m}^{C *}}{\partial a}>0, \frac{\partial D_{p}^{C *}}{\partial a}<0, \frac{\partial \pi_{p}^{C *}}{\partial u}<0, \text { 当 } 0<a<a_{1} \text { 时, } \frac{\partial \pi_{m}^{C *}}{\partial a}<0 \\
\frac{\partial s_{1}^{C *}}{\partial c}>0, \frac{\partial D_{m}^{C *}}{\partial c}>0, \frac{\partial D_{p}^{C *}}{\partial c}>0, \frac{\partial \pi_{p}^{C *}}{\partial c}>0, \text { 当 } 0<c<c_{1} \text { 时, } \frac{\partial \pi_{m}^{C *}}{\partial c}>0
\end{gathered}
$$

Conclusion 3 shows that first, same as conclusions 1 and 2, as service sensitivity increases, the service level increases, product demand increases, and the profits of the manufacturer and the e-commerce platform increase. Second, as the proportion of commission increases, the platform service level increases, the demand for platform channel products increases, the e-commerce platform's profit increases, the direct sales channel demand decreases, and the manufacturer's profit decreases. Third, with the increase in the proportion of migration, the service level decreases, the platform channel demand decreases, the platform's profit decreases, and the direct sales channel demand increases. When the proportion of migration is high, the manufacturer's profit increases. Fourth, as the unit cost of direct selling increases, the platform service level increases, the demand of each channel increases, and the platform's profit increases. Within a certain unit cost range, the manufacturer's profit increases.

\subsection{Direct sales-self-operated store marketing model}

Under the direct sales-self-operated store marketing model, the demand functions of the manufacturer's direct sales channel and the e-commerce platform sales channel are as follows:

$$
\begin{gathered}
D_{m}\left(p_{p}, p_{m}\right)=a-p_{m}+\beta p_{p} \\
D_{p}\left(p_{m}, p_{p}, s_{2}\right)=(1-a)-p_{p}+\beta p_{m}+\theta s_{2}
\end{gathered}
$$

The profits of the manufacturer and the e-commerce platform are as follows:

$$
\begin{gathered}
\pi_{m}=\left(p_{m}-c\right) D_{m}+w D_{p} \\
\pi_{p}=\left(p_{p}-w\right) D_{p}-\frac{s_{2}^{2}}{2}
\end{gathered}
$$

The solution method of this model is the same as in 3.2, so it will not be repeated here. The optimal decision is as follows: 


$$
\begin{gathered}
s_{2}^{D *}=\frac{(a-1-\beta c) \theta}{\theta^{2}-4}, D_{p}^{D *}=\frac{a-\beta c-1}{\theta^{2}-4}, \pi_{p}^{D *}=\frac{(1-a+\beta c)^{2}}{2\left(4-\theta^{2}\right)} \\
p_{p}^{D^{*}}=\frac{6-2 \beta^{2}+\beta c\left(2-2 \beta^{2}+\theta^{2}\right)+a\left(\beta\left(4+2 \beta-\theta^{2}\right)-6\right)}{2\left(\beta^{2}-1\right)\left(\theta^{2}-4\right)} \\
p_{m}^{D *}=\frac{4\left(a+c+\beta-a \beta-c \beta^{2}\right)-\left(a+c-2 \beta^{2} c\right) \theta^{2}}{2\left(\beta^{2}-1\right)\left(\theta^{2}-4\right)} \\
w^{D *}=\frac{2-2 a(\beta-1)^{2}+2 \beta\left(\beta+c\left(\beta^{2}-1\right)+(c-a) \beta^{2} c\right) \theta^{2}}{2\left(\beta^{2}-1\right)\left(\theta^{2}-4\right)} \\
D_{m}^{D *}=\frac{-2 \beta+a\left(-4+2 \beta+\ddot{\theta}^{2}\right)-c\left(-4+2 \beta^{2}+\theta^{2}\right)}{2\left(\theta^{2}-4\right)} \\
\pi_{m}^{D *}=\frac{(3 \beta-1+c(1+\beta)(3 \beta-4)))+8(a-c)\left(c+a(\beta-1)-\beta-\beta^{2} c\right) \theta^{2}+(a-c)^{2} \theta^{4}}{4\left(\beta^{2}-1\right)\left(\theta^{2}-4\right)^{2}}
\end{gathered}
$$

Conclusion 4: In the direct sales-self-operated store marketing model,

$$
\begin{gathered}
\frac{\partial s_{2}^{D^{*}}}{\partial \theta}>0, \frac{\partial D_{P}^{D *}}{\partial \theta}>0, \frac{\partial D_{m}^{D *}}{\partial \theta}>0, \frac{\partial \pi_{P}^{D *}}{\partial \theta}>0, \frac{\partial \pi_{m}^{D *}}{\partial \theta}>0 \\
\frac{\partial s_{2}^{D^{*}}}{\partial a}<0, \frac{\partial D_{P}^{D^{*}}}{\partial a}<0, \frac{\partial D_{m}^{D^{*}}}{\partial a}>0, \frac{\partial \pi_{P}^{D^{*}}}{\partial a}<0, \frac{\partial \pi_{m}^{D *}}{\partial a}>0 \\
\frac{\partial s_{2}^{D^{*}}}{\partial c}>0, \frac{\partial D_{P}^{D *}}{\partial c}>0, \frac{\partial D_{m}^{D^{*}}}{\partial c}>0, \frac{\partial \pi_{P}^{D *}}{\partial c}>0, \text { 当 } 0<c<c_{2} \text { 时, } \frac{\partial \pi_{m}^{D *}}{\partial c}>0
\end{gathered}
$$

Conclusion 4 shows that first, with the increase of service sensitivity and service level, the demand of each channel increases, and the profits of the manufacturer and the e-commerce platform increase. Second, with the increase of the migration ratio, the service level decreases, and the demand for the platform channel decreases. With declining platform's profit, the demand for the direct sales channel increases, and the manufacturer's profit increases. Third, as the unit cost of the direct selling channel increases along with the service level, the demand for each channel increases, and the profits of the manufacturer and e-commerce platform increase.

Combining conclusion 1 to 4 , the following conclusions can be drawn:

The corollary is that in a single marketing model, the platform service level affects the profits of the manufacturer and the e-commerce platform, having a positive relationship. When direct sales channels are added, the increase in the platform service level will also increase the profit of the e-commerce platform and plays an indirect effect on the profit of the manufacturer.

\section{Comparative analysis}

Combined with the optimal decision obtained above, the difference analysis method is used to compare the profits of the manufacturer and the e-commerce platform under the four different marketing models to explore the selection of their marketing models. At the same time, the changes in service levels and services can be compared to determine the impact of service levels on decision-making. Then, the marketing models that manufacturers and e-commerce platforms adopt under what kind of conditions are analyzed. 


\subsection{Comparative analysis of the marketing model of a single flagship store and a single self-operated store}

Conclusion 5: $\pi_{m}^{A *}>\pi_{m}^{B^{*}}, \pi_{p}^{A^{*}}<\pi_{p}^{B^{*}}, s_{1}^{A^{*}}<s_{2}^{B^{*}}$.

From conclusion 5, it can be seen that the manufacturer's profit under the flagship store marketing model is higher than that of the self-operated store marketing model, while the profit of the e-commerce platform is the opposite. The service level under a single self-operated store is higher than that of a single flagship store. To further explain, for manufacturers who are unable to open direct sales channels, they are more inclined to open flagship stores to sell products on e-commerce platforms while e-commerce platforms tend to build self-operated stores. At this time, e-commerce platforms have more advantages. They can control the entry of manufacturers and force manufacturers to use their self-operated channels. Manufacturers can then sign agreements to guarantee benefits.

Conclusion 6: $\pi_{m}^{D *}>\pi_{m}^{B *}$, when $\mathrm{a}<\beta \mathrm{c}, \pi_{p}^{D *}>\pi_{p}^{B^{*}}, s_{2}^{D *}>s_{2}^{B *}$.

It can be seen from conclusion 6 that when the e-commerce platform is self-operating, the manufacturer's opening of a direct sales channel will always increase the manufacturer's own profit, and it will not be harmed by the increase in the direct sales cost. However, only when certain conditions are met, the opening of a direct sales channel will benefit the e-commerce platform and stimulate the service level of the e-commerce platform. It can be further explained that when e-commerce platforms are self-operating, capable manufacturers will build their own direct sales channels to increase their profits, but when consumers have a high preference for direct sales channels, it will detract the interests from e-commerce platforms. At this time, e-commerce platforms are at a disadvantage, hence they can sign agreements with manufacturers to avoid damage to their own profits.

Conclusion 7: $\pi_{m}^{C *}>\pi_{m}^{A^{*}}$, if $c>c_{3}, \pi_{p}^{C *}>\pi_{p}^{A^{*}}$, if $c>c_{4}, s^{C *}>s^{A^{*}}$.

It can be seen from conclusion 7 that while manufacturers build flagship stores on e-commerce platforms, they can increase their profits by building their own direct sales channels. Similarly, only when certain conditions are met, the opening of direct sales channels will benefit the e-commerce platforms and stimulate their service levels.

Combining with conclusion 6 to further explain, when manufacturers have the ability, no matter what marketing model they adopt on e-commerce platforms, they would choose to build their own direct sales channels. Hence, the e-commerce platforms would be at a disadvantage due to competition, and at this time, as strong retailers, they can choose to sign agreements with manufacturers to protect their interests.

Conclusion 8: $\pi_{m}^{D *}<\pi_{m}^{C *}, \pi_{p}^{D *}>\pi_{p}^{C *}, s^{D^{*}}>s^{C *}$.

It can be seen from conclusion 8 that when manufacturers have the ability to build their own direct sales channels, manufacturers would choose to establish flagship stores to sell products on e-commerce platforms, while e-commerce platforms are more inclined to open self-operated and direct sales under the service level of self-operated stores.

Combining conclusions 6 and 7, it further explains that when manufacturers choose to build their own direct sales channels, it may damage the income of e-commerce platforms to a certain extent. E-commerce platforms, in a strong position, would choose to establish self-operated stores as much as possible to reduce losses. At this time, the manufacturers and e-commerce platforms need to sign contracts, such as revenue sharing, commissions, etc.

\section{Numerical analysis}

Based on the previous analysis as well as satisfying the above equilibrium solution and propositions, in order to intuitively compare and analyze the influence of consumer service sensitivity coefficients on 
system decision-making under different marketing models, simulation experiments are used. The parameters are set as $a=0.2, \beta=0.3, c=1.0$, and $u=0.15$. The e-commerce platform service level, manufacturer's profit, and the relationship between the e-commerce platform's profit with the service sensitivity coefficient, $\theta$, in the model analysis are further verified.

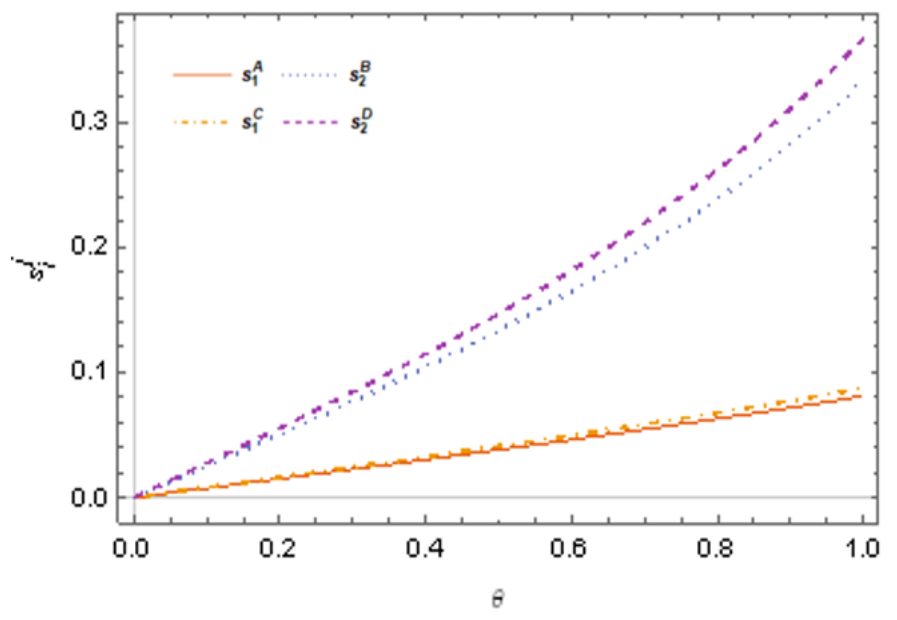

Figure 2. Impact on service level

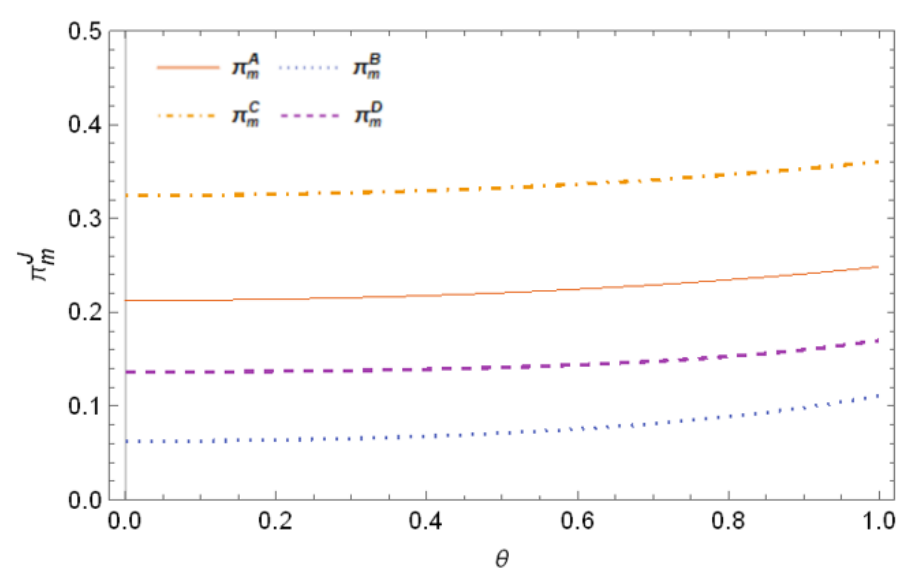

Figure 3. Impact on manufacturer's profit

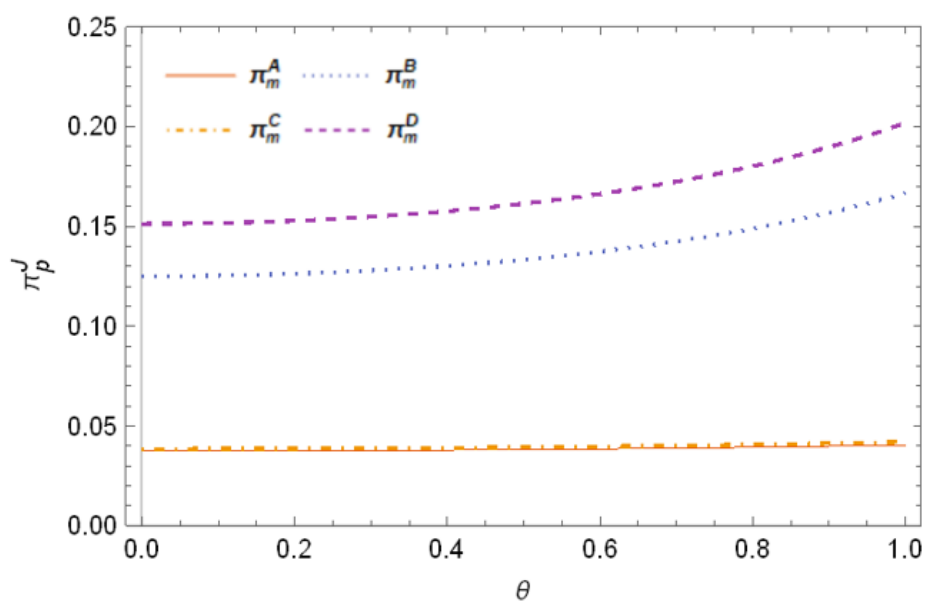

Figure 4. Impact on the profit of e-commerce platform 
Figure 2, Figure 3, and Figure 4 show that the service sensitivity coefficient, $\theta$, promotes the profit and service level of e-commerce platforms as well as the profit of manufacturers to varying degrees. The service levels of flagship stores are significantly lower than those of the self-operated stores. The opening of direct sales channels also has an incentive effect on service levels. However, the increase in consumer sensitivity greatly improved the competitiveness of e-commerce platforms with superior service levels. In addition, the figures above also compare the decisions of the four marketing models to a certain extent. It is inferred that under certain conditions, the service level of self-operated stores is slightly higher than that of flagship stores. When it is possible to open direct sales channels with the ability to control costs, manufacturers tend to open direct sales channels while opening flagship stores on e-commerce platforms, whereas e-commerce platforms are more inclined to establish exclusive self-operated stores.

\section{Conclusion}

This article divided the supply chain marketing model into a single flagship store, a single self-operated store, a direct sales-flagship store, and a direct sales-self-operated store according to the characteristics of online sales channel. On this basis, it considered the value of service level in decision-making, and introduced factors, such as price sensitivity, channel preference, and unit cost of direct selling. This article used the Stackelberg game theory to establish a marketing game model between manufacturers and ecommerce platforms in addition to the numerical analysis and other methods to compare and analyze the manufacturer's profits, e-commerce platform profits, and the service level of different marketing models. The conclusions are as follows:

(1) In the face of service-sensitive consumers, the opening of direct sales channels by manufacturers can stimulate platform service levels under certain conditions, thereby increasing the profits of both, manufacturers and platforms. At this time, manufacturers should choose to open direct sales channels while e-commerce platforms should choose self-operated stores based on service advantages.

(2) For e-commerce platforms, whether manufacturers have the ability to build their own direct sales channel or not, the self-operated model is the best decision for e-commerce platforms.

(3) Manufacturers and e-commerce platforms can easily lead to a "zero-sum" situation by maximizing their respective interests. Both parties should formulate profit distribution contracts to achieve a winwin situation.

\section{Disclosure statement}

The authors declare that there is no conflict of interest.

\section{References}

[1] Khouja M, Park S, Cai GG, 2010, Channel Selection and Pricing in the Presence of Retail-Captive Consumers. International Journal of Production Economics, 125(1): 84-95.

[2] Chiang WYK, Chhajed D, Hess JD, 2003, Direct Marketing, Indirect Profits: A Strategic Analysis of Dual-Channel Supply-Chain Design. Management Science, 49.

[3] Kumar N, Ruan R, 2006, On Manufacturers Complementing the Traditional Retail Channel with a Direct Online Channel. Quantitative Marketing and Economics, 4(3): 289-323.

[4] Yan Y, Zhao R, Liu Z, 2018, Strategic Introduction of the Marketplace Channel under Spillovers from Online to Offline Sales. European Journal of Operational Research, 267(1): 65-77.

[5] Vibhanshu A, Kinshuk J, John ZZ, 2012, To Platform-Sell or Resell? Channel Structures in Electronic Retailing. SSRN Electronic Journal. 
[6] Wang L, Song H, Wang Y, 2017, Pricing and Service Decisions of Complementary Products in a DualChannel Supply Chain. Computers \& Industrial Engineering, 105: 223-33.

[7] Wu CH, 2012, Price and Service Competition between New and Remanufactured Products in a TwoEchelon Supply Chain. International Journal of Production Economics, 140(1): 496-507.

[8] Dan B, Zhang S, Zhou M, 2018, Strategies for Warranty Service in a Dual-Channel Supply Chain with Value-Added Service Competition. International Journal of Production Research, 56.

[9] Zhou YW, Guo J, Zhou W, 2018, Pricing/Service Strategies for a Dual-Channel Supply Chain with Free Riding and Service-Cost Sharing. International Journal of Production Economics, 196: 198-210.

[10] Chen X, Wang X, Jiang X, 2016, The Impact of Power Structure on the Retail Service Supply Chain with an O2O Mixed Channel. Journal of the Operational Research Society, 67(2): 294-301. 